\title{
Interculturalidad-globalidad, ¿compatibles con la enseñanza del español y del arte mexicano?
}

Silvia Fernández Hernández*

\begin{abstract}
Resumen: Este trabajo consta de tres partes. La primera expone algunas reflexiones teóricas sobre el fenómeno de la interculturalidad en la globalidad. La segunda presenta experiencias útiles para enfrentar los modelos de interculturalidad en la enseñanza del español y la cultura a extranjeros en México. La tercera plantea tres paradigmas de la interculturalidad en el arte contemporáneo.
\end{abstract}

Palabras clave: enseñanza del español, interculturalidad, globalidad, arte mexicano.

REFLEXIONES TEÓRICAS PRELIMINARES SOBRE EL FENÓMENO INTERCULTURALIDAD-GLOBALIDAD

El sociólogo Néstor García Canclini (2005) ha caracterizado éste fenómeno a partir tres problemas centrales. El primero se refiere a la oposición entre globalidad y localidad, el cual fluctúa entre la concreción de cómo se reorganiza y concibe la economía, la política y la cultura a nivel nacional y a nivel global. Debido a su origen inaccesible; el segundo, trata sobre las dificultades para identificar y localizar las decisiones políticas, económicas y culturales globales, por último, el tercero las consecuencias teórico-metodológicas para resolver los desafíos que suponen armar un rompecabezas transdisciplinario con los datos económicos, políticos y culturales.

Circulan muchas metáforas respecto al concepto de globalización que resultan utópicas, porque no logran integrar los modelos de pensamiento con la realidad de lo que significa la modificación de las identidades y de los patrones culturales de millones de personas o de las realidades subjetivas de los emigrantes.

* Doctora en Historia del Arte. Profesora de tiempo completo en el Centro de Enseñanza para Extranjeros de la Universidad Nacional Autónoma de México (UNAM). Tiene 37 años de experiencia docente. Forma parte del Seminario Posdoctoral "La enseñanza del arte en México", coordinado por el doctor Aurelio de los Reyes, en el Instituto de Investigaciones Estéticas de la UNAM. 
Sí analizamos el problema con mayor detenimiento, nos percataremos de que sólo una porción del mundo, el financiero-político, piensa en un mundo de globalización circular; los demás, lo concebimos como una globalización tangencial, por el hecho real de la desigualdad en el acceso a lo que se considera una economía y una cultura global.

La interculturalidad y la migración son procesos que han existido en toda la historia de la humanidad. Se puede afirmar que todas las culturas han tomado unas de otras para su desarrollo. Por ello, es importante distinguir en qué consiste la diferencia con el fenómeno actual. La interculturalidad en la era de la globalización, se refiere a la aceleración cuantitativa y cualitativa de la confrontación que supone la diversidad cultural en la convivencia diaria. (Fig.1)

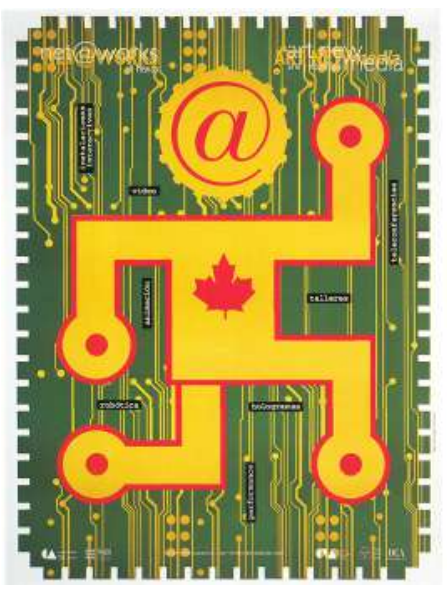

Figura 1

Indudablemente, la globalización de los medios de comunicación y la industria de la cultura han modificado la percepción que tenemos del espacio geográfico y la identidad nacional. Las megaciudades — como la ciudad de México-, han visto diluir sus valores nacionales, por los nuevos sincretismos culturales que se forman con la interacción de los medios de información y la tecnología, en donde la homogeneidad de la identidad de un país, se construye, no sólo con los símbolos culturales locales o nacionales, sino también con los transnacionales. Sin embargo, la nueva articulación entre lo local, lo nacional y lo global se presenta con rasgos diferentes en las distintas capitales cosmopolitas globalizadas de Europa, Asia, Norteamérica y América Latina.

Sabido es que desde el siglo XVI la interacción intercultural entre Europa, América Latina y Norteamérica se desarrolló con las migraciones de carácter colonial, mercantil, cultural y político, proceso que se ha intensificado con las migraciones actuales. Lo importante de ello es destacar cómo se han configu- 
rado ciertos patrones generales para ver y relacionarse con el otro, se ha forjado una confrontación de identidades donde los del norte, europeos y norteamericanos, discriminan a los del sur, latinoamericanos; a su vez, los latinos los admiran, pero los ven con recelo y resentimiento. Resulta paradójico que mientras los procesos culturales de estos grupos, los alejan en términos generales, los intercambios interculturales mediáticos crecen con rapidez. Por lo tanto, el proceso de la interculturalidad global enfrenta dificultades importantes para conciliar las diferentes ideologías y prácticas socio-políticas, y al mismo tiempo, lograr acuerdos entre naciones distintas como una necesidad globalizadora.

Néstor García Canclini (2005: 14) define cuatro modelos de interculturalidad que entran en juego y se entretejen en la realidad actual:

1. El sistema republicano europeo de los derechos universales.

2. El separatismo multicultural de Estados Unidos.

3. Las integraciones multiétnicas de Latinoamérica.

4. La integración intercultural promovida por los medios de comunicación que los cruza.

Agregamos uno a la lista, que no podemos soslayar en nuestro país y en el Centro de Enseñanza para Extranjeros (CEPE):

5. La integración del Oriente a la cultura occidental.

Un ejemplo lo suficientemente ilustrativo de la integración intercultural promovida por los medios de comunicación, aún vigente, es el cartel con los logotipos de la Coca-Cola publicado en 1980, (Fig.2) éste nos indica, el alcance de la distribución del refresco; el poder de la identificación gráfica con el color y letras de un producto, en la comunicación global publicitaria; si se lee de arriba en la dirección de izquierda a derecha está escrito en: español, tahitiano, turco, japonés, francés, chino, hebreo, árabe, griego, ruso, alemán y coreano.

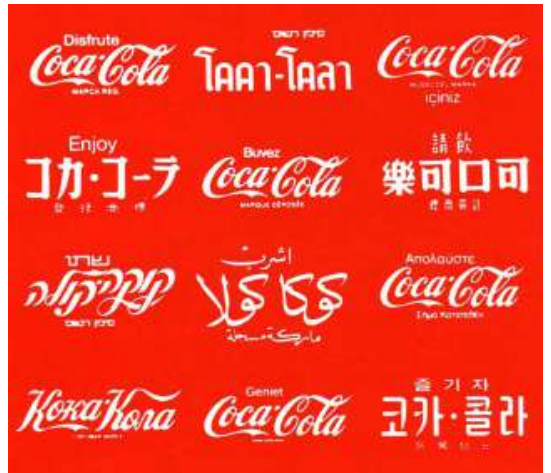

Figura 2 
La globalización e interculturalidad son un hecho, sin embargo, ¿cómo perciben o se apropia cada región de estos procesos?, ¿cuál es la ganancia y cuál es la pérdida latinoamericana frente a los discursos globales de interculturalidad?

La realidad latinoamericana, como la señala García Canclini (2005) se manifiesta en los discursos oficiales de nuestros gobiernos, quienes declaran y admiten que somos naciones pluriculturales y multilíngües, mas no se precisa en qué ámbitos se aplica y en cuáles no. Fidel Tubino, (2005) decano de la Universidad del Perú, apunta que la interculturalidad, sólo se reduce a la esfera educativa, a nivel primaria, en toda la región latinoamericana para ocultar un racismo latente.

En México, la Secretaría de Educación Pública (SEP), el Instituto Nacional de Antropología e Historia (INAH), la Comisión Nacional para el Desarrollo de los Pueblos Indígenas (CDI), el Consejo Nacional de Fomento Educativo, (CONAFE) la Universidad Autónoma Pedagógica (UAP) han puesto énfasis en la educación bilingüe de las comunidades indígenas con la idea de homogeneizarlas respecto a la adquisición del idioma español y alfabetización en el marco de la "cultura nacional", en la que se insertan los grupos indígenas como la parte "folklórica" o "turística". Se privilegian ciertas culturas en el discurso oficial como la maya y mexica, con sus ancestrales centros ceremoniales y museos arqueológicos de interés turístico, en cuanto a los grupos indígenas actuales, se les limita a una reducida participación social de carácter folklórico.

Cabe señalar que en México, aunque son numerosas las instituciones quienes emprenden esa educación, imparten una educación inferior al promedio general, inclusive, centrada en ciertas zonas rurales que se privilegian de acuerdo a las visitas oficiales de los presidentes en turno, con recursos que no se sostienen de una manera permanente. Otro aspecto, es la discriminación de esos mismos indígenas emigrantes asentados en las periferias de las ciudades de México, Guadalajara y los estados de Chihuahua, Puebla, México, entre los más importantes.

Estas políticas oficiales de biculturalidad-multiétnica ponen énfasis en la lengua autóctona y su relación con el español, pero ignoran por completo la relación paralela e indisoluble de la cultura. ¿Cómo hablar de "una cultura nacional" cuando se desprecia e ignora a esos grupos?, ¿desde qué parámetros se mide la cultura?, ¿cómo enfrentar la interculturalidad con otros países y regiones sin una revaloración de lo propio?

Debido a ello, en la reunión sobre el mayor proyecto de Educación en América Latina y el Caribe organizada por la UNESCO, [en 1983] donde América Latina decidió de manera consensuada dejar el concepto de educación bicultural por el de educación intercultural. Entendido en la región como el contacto y la interrelación entre las lenguas y las culturas. (Tubino, 2005). 
¿Cómo enfrentar los modelos de interculturalidad de manera práctica en LA doCencia?

La diversidad genticilia que nos muestran las estadísticas del CEPE, nos manifiestan que en el año 2006 asistieron estudiantes de 78 nacionalidades. Si las congregamos en tres grandes grupos culturales - de acuerdo con el enfoque pedagógico intercultural y sus modelos-, tenemos que los alumnos procedentes de las culturas occidentales de Europa y Norteamérica representaron el 44 por ciento; los de culturas del Oriente lejano y Oceanía: chinos, japoneses, coreanos, vietnamitas, tailandeses y filipinos constituyeron el 49 por ciento y por último, discípulos de las culturas del medio Oriente y africanas: árabes, persas, indios y africanos sumaron el seis por ciento. (López, 2009)

La diversidad de alumnos puede ser abrumadora para todos los profesores de español y cultura del CEPE, si consideramos el hecho de que el maestro del Centro no tiene como requisito para impartir clases, ser políglota. Sin embargo, debe tener la aptitud para comprender la heterogeneidad de su grupo de alumnos como punto de partida esencial para la instrucción. Al mismo tiempo, como la enseñanza del idioma español ocupa el centro, entre las distintas lenguas de origen de sus alumnos, es un verdadero reto para el docente comprender en qué consisten las diferencias culturales y lingüísticas en que ellos se expresan, piensan y sienten. Enfrentar este desafío magisterial resulta fascinante, a la vez que nos convierte en auténticos especialistas.

Las lenguas y sus escrituras no son estáticas; evolucionan, se transforman y ramifican. Casi todas las lenguas de la cultura occidental y árabe comparten un mismo origen: el fenicio temprano; los árabes y judíos tienen muchas raíces lingüísticas y de escritura comunes a pesar de su ancestral desavenencia. De las raíces chinas se pueden establecer tres grandes ramas; la primera, el chino mandarín y el cantones. El japonés, coreano y mongol constituyen otra de las ramas y en la última está el vietnamita. En el origen de las escrituras mesoamericanas: náhuatl, maya y mixteco-zapoteco, las tres encuentran sus raíces en la protoescritura olmeca.

Las lenguas y las escrituras son frecuentemente re-inventadas y generalmente extendidas en forma vigorosa. La política, la religión y el comercio son los factores cruciales aquí. A lo largo de la historia, lingüistas, artistas, visionarios, reyes e, incluso, novelistas y poetas, han diseñado muchas escrituras, pero los misioneros, maestros, comerciantes, administradores e inmigrantes, son los que en realidad las han esparcido por todos lados. En el mundo globalizado de la actualidad, conquistadores y refugiados son los actores más importantes.

De esta milenaria evolución histórica y transformación de las lenguas y escrituras, por la urgencia y la velocidad en la comunicación del sistema globalizado, la tendencia de la expansión de las mismas se ha modificado en su 
ritmo de la evolución, lo cual provocará en unas cuántas décadas — según los pronósticos internacionales-, que sólo se hablen y escriban unos cientos de lenguas. Surge entonces una competencia entre los países por difundir su lengua, entre las que figura el español. Interés de nuestros alumnos extranjeros para cubrir los requisitos de una segunda lengua, ya sea en el ámbito universitario, comercial y político y quizá como un interés secundario al aspecto anterior.

El punto de partida para nuestras clases en el CEPE es el conocer el interés de nuestros alumnos, teniendo en cuenta lo que la sociedad global les pide. Resulta útil el esquema de José Gimeno Sacristán (2002) que resume los ejes del cambio en el escenario del mundo actual. (Fig. 3)

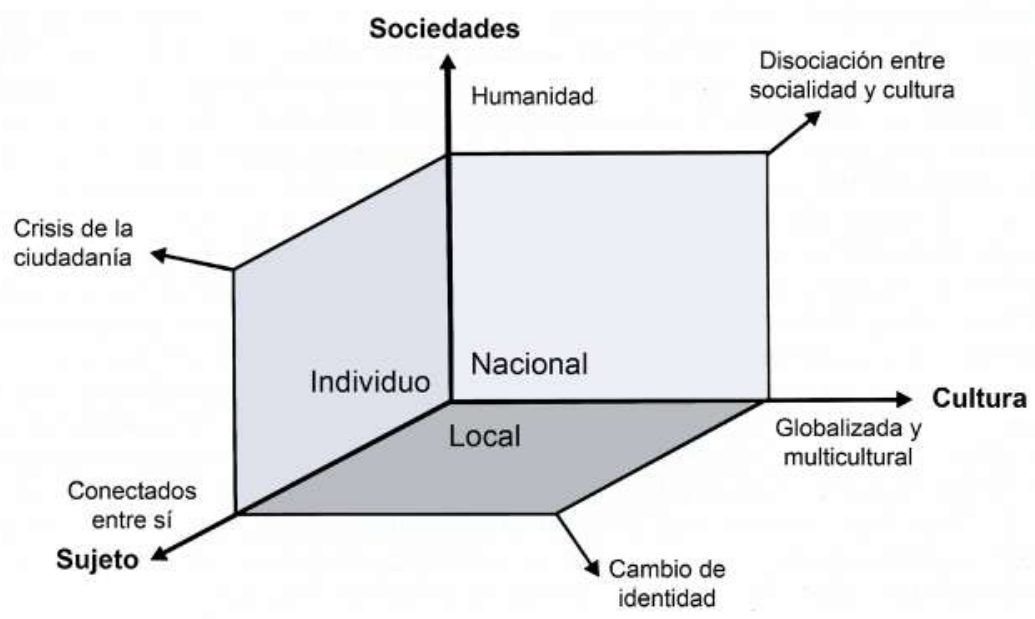

Figura 3

El esquema representa la complejidad individual y social de los cambios a los que están sujetos los grupos humanos actualmente; en un grado más intenso los emigrantes, quienes se enfrentan a sociedades y culturas en las que deben asimilarse para sobrevivir, pero que no necesariamente se identifican con ellas.

Este proceso, ha llevado a algunos autores como Gilíes Lipovetsky (2008) a describir lo que se denomina como "La sociedad de la decepción": entre lo que te ofrece la sociedad de consumo y lo que puedes consumir; lo que consumes y su carácter efímero; la vulnerabilidad de las instituciones y la falta de certeza de seguridad social; el desencanto de la democratización electoral, que ha conducido a los pueblos a promover sus problemas sociales y políticos, ante las políticas estatales inciertas; así como el desaliento de los emigrantes al confrontar que el paraíso de las oportunidades en los países europeos y de Norteamérica no es tal para ellos. 
Los países europeos y de Norteamérica enfrentan, en el rango pedagógico, que su universo conceptual de la "universalidad de su cultura" ha provocado en esta movilidad social masiva, una reafirmación de lo local, de la diferencia, dislocando el etnocentrismo de la cultura occidental. Es por ello, que tratan de integrar desde el punto de vista de la adquisición de la cultura, al enfatizar la interculturalidad, que concibe al sujeto-alumno conectado con otros, ya sea en la sociedad en su dimensión local, nacional o internacional, que lo haga conciente de que la cultura puede apreciarse tanto en su dimensión local como globalizada.

Con la finalidad de que conviva como "ciudadano" en los países a los que emigra. Es en este punto donde debemos enfatizar que se trata de un acercamiento no simétrico, no de igualdad de respeto al otro, sino desde una visión de "desarrollo civilizatorio" del "buen salvaje". Parámetros conceptuales que se asientan resumidos en este segundo esquema, en donde se puntualizan los criterios para la promoción a nivel internacional de la educación intercultural-global. (Fig. 4).

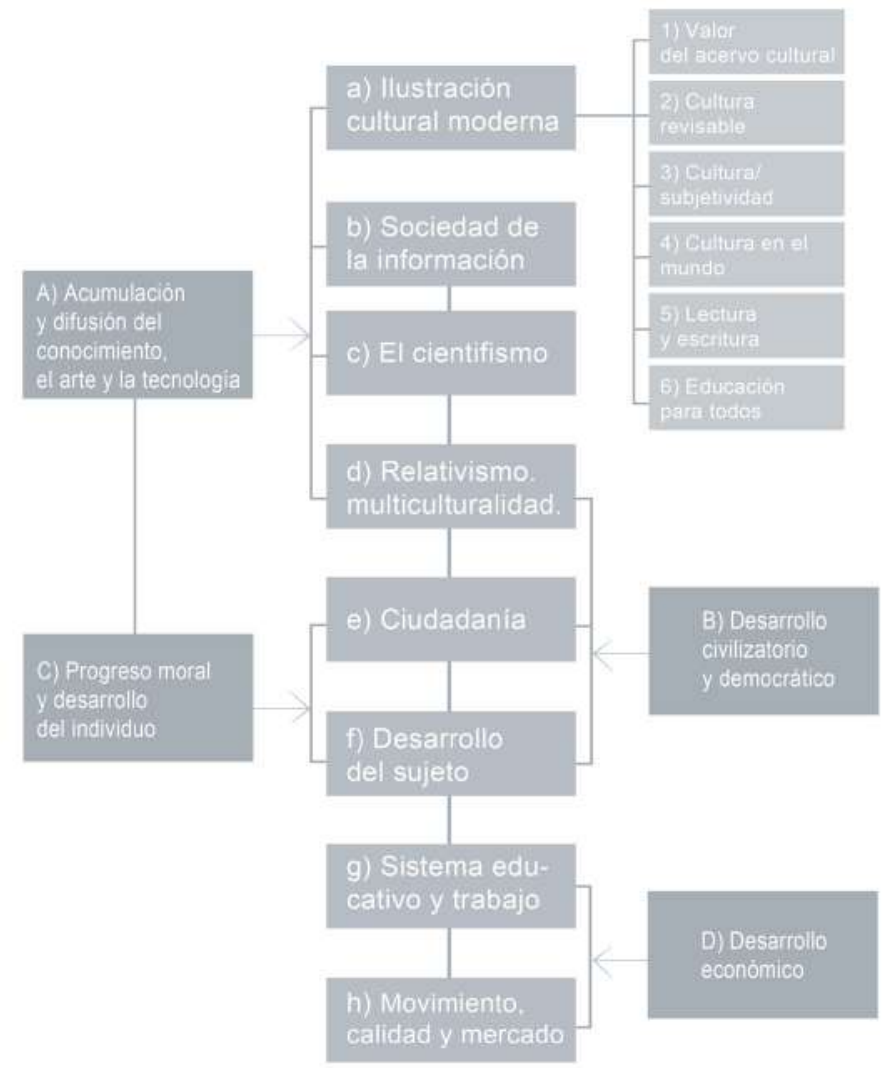

Figura 4 
¿Y Cómo SE HA ABORDAdo El CONCEPTO DE INTERCULTURALIDAD EN EL CEPE?

En el CEPE el concepto de interculturalidad se aborda de una manera pragmática, al tratar de homologar las competencias lingüísticas que requieren nuestros alumnos con el Marco Común de Referencia Europeo. Los problemas surgen cuando se cruzan las fronteras disciplinarias, sin una brújula, al mezclar la "cultura" con las competencias lingüísticas, sin un acuerdo de discusión seria y profunda que defina qué se entiende por cultura nacional, qué parte de la cultura les interesa a los alumnos y cuál queremos transmitir los académicos. Sin reflexionar de una manera interdisciplinaria con los profesores de cultura, qué ejemplos son mejores en calidad de nivel universitario y cuáles son los más pedagógicos; qué información es seria y confiable.

La consecuencia - de esta carencia de diálogo - en nuestros alumnos es una desorientación frente a la cultura nacional, ya que lejos de tratar de adquirirla se distancian de ella. Por referirme sólo a un ejemplo de un tema del libro de español del nivel intermedio, que trata sobre el muralismo mexicano. En el texto hace referencia al movimiento muralista, a un autor de un mural en Ciudad Universitaria, se centra en el friso más complejo de la Biblioteca Central que describe una parte de la visión mesoamericana de la gran Tenochtitlan. La documentación que lee el alumno tiene errores: como afirmar que la vírgula de la palabra, cuando se entrelaza significa fuego. La vírgula de la palabra es un glifo que simboliza cosas distintas, a manera de verbosustantivado: habla, canto precioso, canto florido, fuego, mas nunca, se entrelaza, lo entrelazado se refiere a una de las representaciones ya sea de Quetzalcóatl o el agua que corre. (Fig. 5)

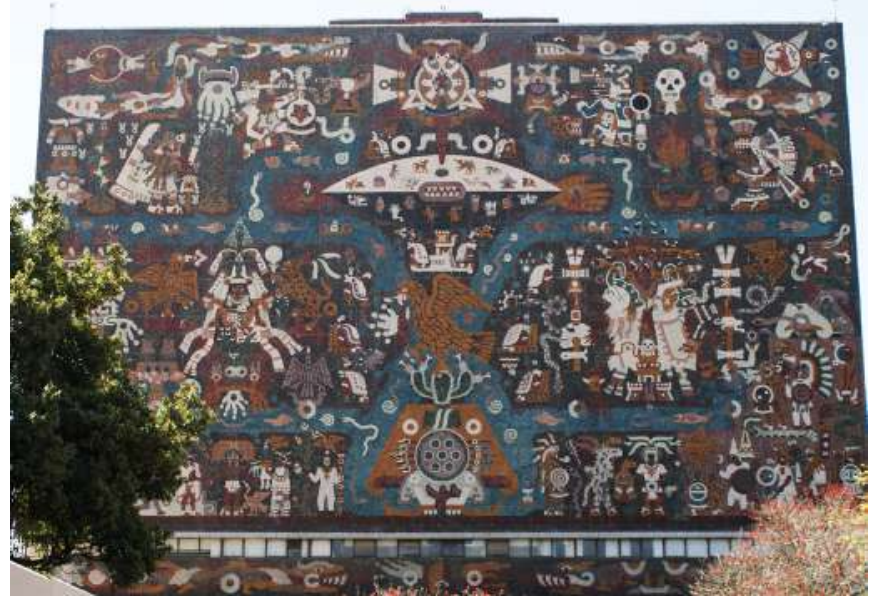

Figura 5 
Lo más grave no es tanto la información errónea, sino además, los ejercicios que el alumno debe resolver, como localizar en una ilustración defectuosa el elemento más difícil que es la representación de Quetzalcóatl. Con la diversidad de preguntas, el alumno debe transitar de la pintura mural, en este caso un mosaico, a la obra del autor y nada menos que a jidentificar glifos prehispánicos!, sin una introducción previa de lo que significa la cosmovisión mesoamericana y en particular la escritura pictográfica. Ya en el conjunto de las preguntas, al alumno no le queda claro si el tema era pintura mural o mosaico, si se trataba de identificar la obra de Juan O'Gorman o la leyenda de Quetzalcóatl.

Por ello es urgente precisar lo qué no debemos hacer los profesores de español y cultura:

- Aplicar mecánicamente un modelo europeo sin poner en una balanza nuestra rica experiencia institucional.

- No trabajar interdisciplinariamente los pares de cultura y de español.

- Utilizar clichés culturales que no están al nivel universitario.

- Trivializar la cultura en sus partes folklorizantes de menor valor cultural.

- Descontextualizar las manifestaciones culturales.

- Usar términos locales de poco valor en un libro de texto.

- Uso de materiales didácticos de cultura sin consultar a los especialistas en cuanto al nivel y a la calidad de las fuentes empleadas en los libros de texto.

En el departamento de Arte del CEPE, para poder enseñar la apreciación estética y la valoración del arte mexicano se parte del contexto histórico. Ya que no podemos hablar de obras de arte sin explicar sus parámetros de concepción y realización, los cuales varían en cada época. Es por ello, que se ha dividido la enseñanza de sus manifestaciones en cinco grandes épocas: la mesoamericana, la virreinal, la decimonónica, la del siglo XX y la del siglo XXI.

Es indispensable para el maestro enterarse de cuál es la idea que los alumnos tienen sobre nuestro país, qué información concreta tienen y sus fuentes. Tiempo invertido en ello que le da un marco al profesor del nivel, intereses y cuáles son los referentes comunes que le servirán de vehículo de comunicación con sus alumnos. Junto a ello, es necesario que el maestro tenga un conocimiento de algunas manifestaciones artísticas de sus respectivos países para establecer en el transcurso de la docencia los puntos de comparación, contraste, tendencias y preferencias, con el propósito de establecer una relación interactiva con ellos, para que la adquisición del conocimiento les sea significativo.

De esta manera, la simetría en la valoración entre el arte de sus países y el nuestro, le facilita al alumno la libertad de expresar de una forma más espontánea lo que conoce y aprecia, a la vez de atreverse a conocer lo nuevo o diferente. 
De acuerdo a la experiencia, hay una relación directa entre el nivel de español y el nivel de las manifestaciones artísticas, que varían en grados de complejidad conceptual para su apreciación. Con base en ello, entre menor nivel de español, se requiere de mayor número de imágenes, para explicar un concepto, con ejercicios en clase que lo refuercen, aunado a lecturas adecuadas, como sería el nivel básico de español.

Para los alumnos del nivel Intermedio, si se parte de lo general a lo particular es mucho más didáctico. Por ejemplo, si se pretende que el alumno aprecie y disfrute una pintura de Rufino Tamayo, se le explica en términos generales cuáles son los elementos importantes de la teoría del color, se le muestran ejemplos para que los aplique y después, se contextualiza históricamente al autor, sólo entonces se le presentan sus obras para que las vea, sienta, analice, y con ello, que él mismo descubra sus características y emita finalmente una valoración estética.

A mayor nivel de español, mayores posibilidades de analizar las imágenes, por lo tanto, al tener ya una mayor capacidad expresiva, los alumnos deben tener una participación más directa en clase, que se base en investigaciones sencillas extra clase y se orienten con las antologías preparadas por el maestro para exponer alguna obra de arte o tema del programa. Como sería el caso de los alumnos del nivel avanzado o superior.

\section{TRES PARADIGMAS DE LA INTERCULTURALIDAD EN EL ARTE}

El primero ejemplifica la relación entre los modelos interculturales estadounidense y mexicano. Como ejemplo, está el curioso sombrero campero, tan popular en los estados de San Luís Potosí, México y de Texas, Estados Unidos, el cual manifiesta con claridad el fenómeno de prestar y modificar la forma y resignificar el modelo tradicional por el nuevo atavío en la interculturalidad entre ambas regiones fronterizas.

El origen del sombrero es completamente mexicano, de los rancheros norteños. Su materia prima es de una palma denominada popularmente jipijapa. Su tejido es una técnica ancestral, muy representada en los glifos prehispánicos. La forma original de la copa y el ala se han modificado, la copa se ha sumido en el centro y está adornada con rectángulos rítmicos calados, el ala se ha doblado hacia arriba en los lados, y hacia abajo, al frente y en la parte posterior. El color ha dejado su natural amarillo por un Ilamativo verde. El adorno ha dejado de ser una cinta de cuero por cuentas engarzadas. Y la textura flexible de la palma se ha endurecido para fijar la nueva forma.

¿A qué obedecen tantos cambios? De ilustraciones coloniales, litografías del siglo XIX y fotografías del siglo XX, podemos afirmar que dichos sombreros fueron fabricados por siglos con muy pocas variantes. Fueron muy apreciados 
tanto en el norte de México como en el sur de Estados Unidos, como lo testifica fehacientemente el idioma inglés, que adoptó la palabra sombrero para referirse a los sombreros mexicanos y distinguirlos del hat de estilo europeo. (Fig. 6).

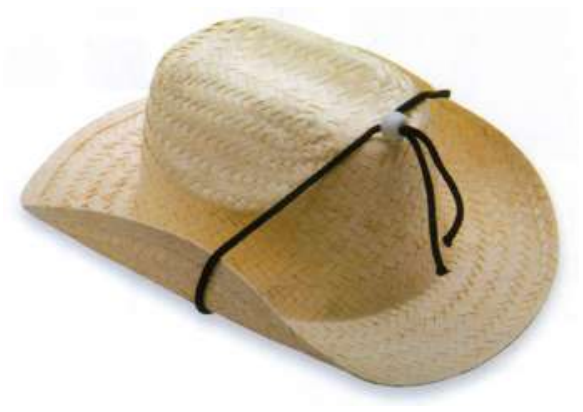

Figura 6

En las últimas décadas del siglo XX, la migración bracera del norte de México no sólo se extendió, sino que se intensificó. Los emigrantes mexicanos al regresar temporalmente a San Luís Potosí han cambiado el nombre del sombrero por el de "campera", han modificado la forma a un estilo tejano, conservando el tejido, el adorno y el color más mexicano.

Otro prototipo de la interculturalidad en la globalidad, lo representa el símbolo de la moneda de la Unión Europea: el euro $(€)$, que significa la identidad de la misma, así como la asimilación de una imagen multinacional. Yves Thibault de Silguy quien fungía como comisario de Asuntos Económicos de la Unión Europea acuñó el nombre "euro", por su fonética fácil y sencilla. El diseñador del símbolo fue el francés Jean-Pierre Malivoir, quien remontó la historia de la civilización europea para buscar el origen de la letra E y cuyos antecedentes datan del siglo 1500 a. C., en la escritura sinaítica. Esta letra se representaba en la protoescritura con el símbolo de un hombre con los brazos levantados. En su evolución hacia la escritura hebrea y fenicia, los fenicios la simplificaron, como se observa en las figuras 7 y 8.
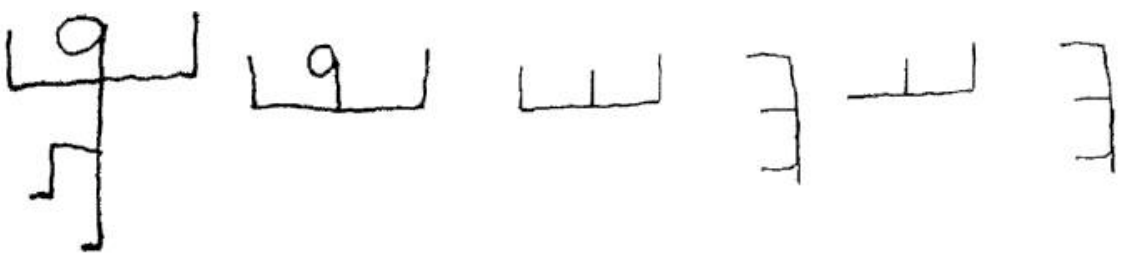

Figura 7 

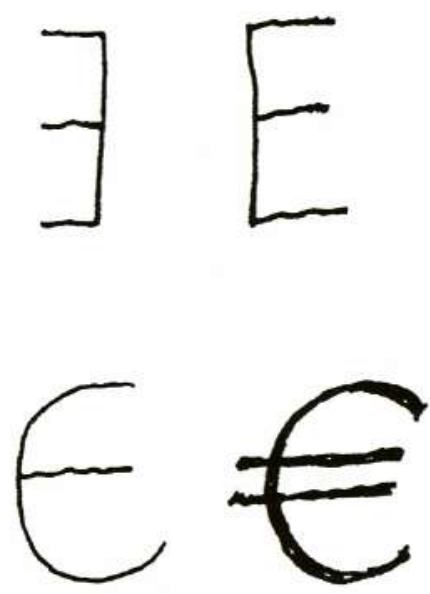

Figura 8

En el siglo VIII a. C. la hé en las escrituras griegas antiguas devino en épsilon, pero con la línea en "bustróferon",' es decir, líneas orientadas hacia la izquierda, hasta que se estabilizó su trazo en el siglo $V$ a. C. en el alfabeto occidental, utilizado para el latín hasta la actualidad. Jean-Pierre Malivoir, redondeó el trazo en forma semicircular, para hacerlo suave y acorde con el símbolo de la bandera de la Unión Europea que es un círculo de estrellas; añadió al semicírculo una línea horizontal y las alargó las dos horizontales en el trazo mediano, para darle con su paralelismo, un efecto de equilibrio económico con la afiliación de sus asociados.

Por último, un paradigma musical de la integración intercultural promovida por los medios de comunicación, que traspasa las barreras culturales, pues funde de una manera extraordinaria, en una pieza musical; talentos distantes que antes no se hubieran imaginado posibles.

Hace 50 años nadie hubiera supuesto que un compositor brasileño reinterpretara a Juan Sebastián Bach, pues el estereotipo había sido considerar a la música brasileña y sus compositores únicamente con ritmo de Samba. Las primeras reinterpretaciones de la música de Bach las hicieron los jazistas estadounidenses.

En 1945 el brasileño Heitor Villa-Lobos (Fig. 9) rescató la gran herencia musical de uno de los artistas más importantes de la historia y fundió su melodía clásica con la textura de la música folklórica brasileña en la composición de nueve suites, que bautizaron en 1986, los medios masivos de la industrial cultural, en la comunicación global como Bachianas Brasileiras. Quizá el propio Heitor VillaLobos nunca hubiera llegado a ser tan conocido sin la difusión de los medios masivos con la tecnología del disco compacto.

1 Vid., Robinson, A. (2000) 


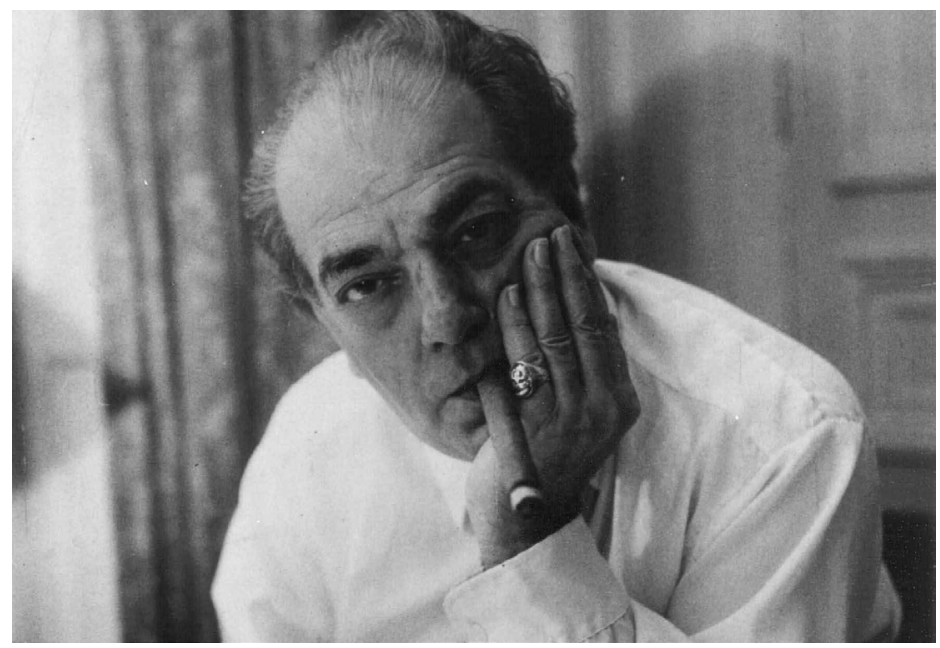

Figura 9

Tampoco hubiera imaginado que en Estados Unidos en los años sesenta, con su separatismo multicultural, un cantante de color se saliera del estereotipo y dejara de cantar jazz o blues para interpretar una obra de música clásica, como lo ha hecho Barbara Hendricks (Fig. 10) con su extraordinaria voz.

Paradigma sí, las Bachianas Brasileiras, de la integración intercultural-global de los medios masivos de comunicación; cuando el compositor es brasileño, la intérprete una soprano de color estadounidense, el director de la orquesta un mexicano, Enrique Bátiz (Fig. 11) dirigiendo a una orquesta inglesa la Royal Philharmonic, en una superproducción hecha en Francia, distribuida por todo el mundo.

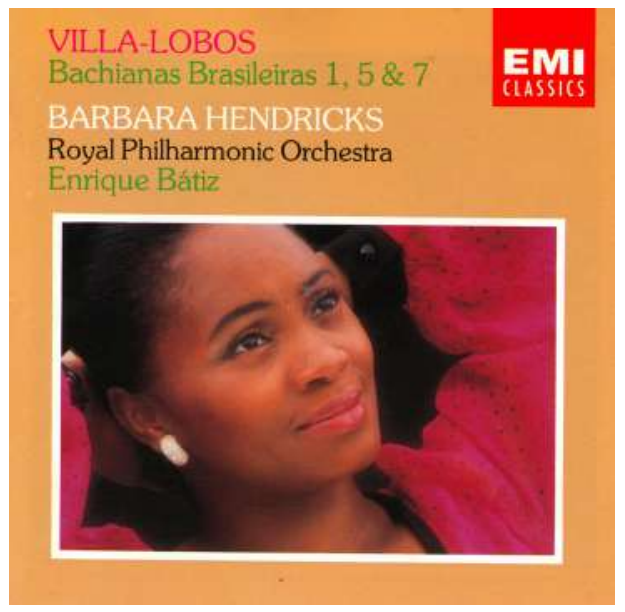

Figura 10 


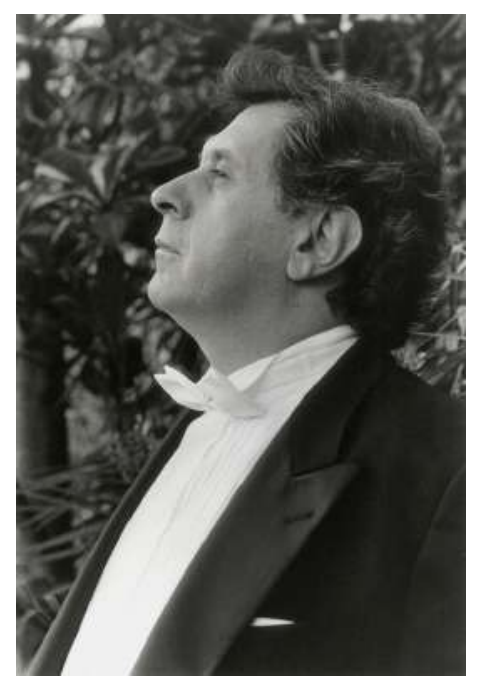

Figura 11

Infinidad de ejemplos podemos presentar, lo importante es contextualizarlos y darles un propósito pedagógico adecuado al nivel de español de nuestros alumnos. Confío en que a través de este trabajo se aclare que el enfoque intercultural en la enseñanza del español y la cultura a extranjeros, no funciona sin una planificación junto al trabajo interdisciplinario entre los docentes del Centro de Enseñanza para Extranjeros. 
BibLIOGRAFÍA

Costa, J. (2001) Si Europa fuera una marca. Habitat, 8, (8). San Luís Potosí: Universidad Autónoma de San Luís Potosí.

García CAnCLINI, N. (2005) La globalización imaginada. Buenos Aires: Paidós.

LIPOVETSKy, P., (2008) La sociedad de la decepción. Entrevista con Bertrand Richard. Barcelona: Anagrama.

LÓPEZ, E., (2009) Resumen estadístico de las nacionalidades de los estudiantes. 2001-2008. Sistema del departamento de Servicios Escolares del Centro de Enseñanza para Extranjeros de la UNAM. México.

MegGs, P. (2000) Historia del diseño gráfico. México: McGraw-Hill.

Robinson, A., (2000) The story of writing. Alphabets, hieroglyphs \& pictograms. Londres: Thames \& Hudson.

SCARISTÁN, J. (2002) Educar y convivir en la cultura global. Las exigencias de la ciudadanía. (2da. ed.) Madrid: Morata.

TuBino, F., (2005) La praxis de la Interculturalidad en los Estados Nacionales latinoamericanos. Cuadernos Interculturales, julio-diciembre, 3, (5). Viña del Mar: Universidad de Valparaíso, p. 84.

Vitla-Lobos, H. (1986) Bachianas Brasileiras 1,5 \& 7. Barbara Hendricks. Hayes Middlesex England: EMI Classics Records. 
REFERENCIAS ICONOGRÁFICAS:

Fig. 1. Olivares, E. (1997) 100 Carteles Mexicanos. México: Conaculta, p. 102, (Catálogo de exposición).

FIG. 2. Robinson, A. (2000) The story of writing. Alphabets \& pictograms. Londres: Thames \& Hudson, p. 212.

Figs. 3 y 4. Sacristán, J. (2002) Educar y convivir en la cultura global. Las exigencias de la ciudadanía. (2da. ed.) Madrid: Morata, pp. 30, 18.

FIG. 5. Foto de la doctora Silvia Fernández Hernández.

FIG. 6. http://www.atr-digital.es/images/sombrero\%20vaquero.jpg

Figs. 7 y 8. Costa, J. (2001) Si Europa fuera una marca. Habitat, 8, (8). San Luís Potosí: Universidad Autónoma de San Luís Potosí, pp. 23, 25.

FIG. 9. http://www.brazilnyc.com/wp-content/uploads/2009/10/villa-lobos_blog.jpg

Fig. 10. Villa-Lobos, H. (1986) Bachianas Brasileiras 1, 5 \& 7. Barbara Hendricks. Hayes Middlesex England: EMI Classics Records, portada.

Fig. 11. http://pac.unlv.edu/images/press/49_large.jpg 